\title{
CERTIFICACIÓN Y RECERTIFICACIÓN DE ESPECIALISTAS MÉDICOS
}

Según lo establecido por la Ley 19.937 de la Autoridad Sanitaria (1) y el Decreto Supremo 57, que reglamentan lo concerniente a la certificación médica, a partir del 2015 todos los médicos especialistas de Chile dejarán legalmente de serlo y deberán certificarse o recertificarse, según sea el caso.

En Chile basta tener el título de médico cirujano para ejercer en cualquier campo de la medicina. Esto porque no existe en nuestro país una Ley de Especialidades Médicas. Entonces, ¿por qué no se piensa en una iniciativa legal de este tipo? Esa posibilidad no es factible por ahora, porque si legalmente se exige que sólo podrán entregar prestaciones médicas en un campo determinado de la medicina los médicos que cuenten con un título o certificado de especialista, dificultaría las atenciones médicas de todo el país. A modo de ejemplo, en el caso de las cesáreas de urgencia, en regiones lejanas, la mayoría de estas intervenciones son realizadas por un médico general o cirujano general y no por un ginecólogo-obstetra. Por lo tanto, si existiera una Ley de Especialidades otros médicos no podrían atender esa cesárea y la paciente simplemente no recibiría atención y lo mismo ocurriría con la mayoría de las atenciones de urgencia.

La carencia de una ley de especialidades médicas, no implica falta de controles para asegurar la idoneidad profesional y ética del médico. Hasta hoy la forma de garantizar la calidad del profesional es a través de un proceso de certificación otorgado por la Corporación Nacional de Especialidades Médicas (CONACEM). CONACEM, es una institución autónoma creada en 1985 y que hasta la fecha ha certificado a 11.950 médicos de 52 especialidades y subespecialidades (pronto se iniciará la certificación de la subespecialidad de medicina materno fetal, derivada de la especialidad de Obstetricia y Ginecología).

En 2004, fue promulgada la Ley 19.937 que indica que - a diferencia de lo que ocurre hoy - el Ministerio de Salud (MINSAL) deberá establecer un sistema de certificación de especialidades y subespecialidades, que sea diferente al de las universidades, realizado por una institución autónoma (que eventualmente podría ser CONACEM).

Cuatro años más tarde, en 2008, se publica el Decreto Supremo 57, asociado a esta ley, que considera sólo 24 especialidades y 18 subespecialidades (42 en total). Es decir, 11 menos de las que actualmente certifica CONACEM. Sin embargo, en la Ley está abierta la posibilidad de que la entidad certificadora acreditada por el MINSAL, solicite a éste la incorporación de las otras subespecialidades, que no están señaladas en el Decreto Supremo 57.

Este mismo Decreto reconoce como especialistas, con una vigencia de 7 años, a contar del 2008, a quienes tengan el título de especialistas, certificado por CONACEM o la Corporación Nacional Autónoma de Certificación de Especialidades Odontológicas (CONACEO) y autoriza, además, a entregar certificados de especialistas a los directores de servicios de salud del país, como a quienes tengan convenios vigentes en FONASA, modalidad de libre elección en una especialidad determinada durante el tiempo de vigencia de los artículos transitorios (dos años). Con esta disposición, queda entendido que todos los títulos y certificados de especialistas caducan el año 2015.

La ley 19.937 y el Decreto Supremo № 57, toman en consideración la complejidad creciente de las especialidades médicas (tanto en conocimientos como en la tecnología) lo cual hace aconsejable tener un sistema de educación continua (recertificación periódica) asegurando que el médico que ejerza una especialidad cuente con la debida y actualizada información, para entregar prestaciones médicas de calidad por parte de las instituciones prestadoras y seguros de salud, y que los pacientes puedan exigir transparentar la información de los médicos especialistas titulados o certificados. Por otro lado, se les entrega a los especialistas una herramienta útil frente a la judicialización progresiva 
de los actos médicos.

Esta Ley no modifica el hecho de que la certificación y la titulación del especialista continuará siendo un acto voluntario de parte del médico. No obstante, la gran diferencia será que la institución que realice el proceso de certificación será acreditada oficialmente por el MINSAL y quienes tengan la certificación serán reconocidos legalmente como especialistas, lo cual es una poderosa garantía de idoneidad frente a los pacientes, y a los médicos les permite en un juicio comprobar la "no temeridad" de sus actos. A esto se suma, que cada vez más, tanto en el área pública como privada, se están estableciendo reglamentos que obligan al médico a contar con su certificación de especialista, como es el caso de los hospitales autogestionados o postulando a la acreditación.

Las Universidades han declarado que no participarán en el proceso de recertificación, por cuanto ellas ven como su función, en el posgrado, la formación de especialistas a través de sus programas acreditados y termina esta participación universitaria con la entrega de los títulos correspondientes. Por otro lado, han expresado que no tienen la organización adecuada para asumir esta función. Así vista la situación, la entidad certificadora acreditada por el MINSAL será, por ley, la encargada del proceso de recertificación, la cual deberá efectuarse cada 5 a 10 años según establece el Decreto Supremo 57 del año 2008.

Atendiendo a su prestigio y experiencia en temas de certificación de especialidades médicas durante 27 años, con más de 400 especialistas trabajando ad honorem en esta tarea, CONACEM debería ser uno de los candidatos o el único, con mayores posibilidades de ser la institución certificadora acreditada por el MINSAL, diferente a las universidades, que exige esta Ley. Reuniones con las autoridades del MINSAL, y acorde a lo que nos han expresado, estamos confiados que CONACEM será considerada a la hora de determinar a la entidad certificadora.

Dr. Patricio Gayán Barba. Maestro de la Gineco-Obstetricia Chilena y Latinoamericana. Ex Presidente Directorio CONACEM.

\section{REFERENCIAS}

1. Ley 19.937. Autoridad Sanitaria. Hallado en: http:// www.supersalud.gob.cl/normativa/571/articles-553_ recurso_1.pdf

2. Decreto Supremo № 57. Reglamento de certificación de las especialidades y subespecialidades de los prestadores individuales de salud y de las entidades que la otorgan. Hallado en: http://www.supersalud. gob.cl/normativa/571/articles-4799_recurso_1.pdf 